\title{
Long-term effect of glucocorticosteroids on neuromuscular blocking in mice
}

\author{
W. F. AR T S A N D H. J. OOSTERH U IS : \\ From the Department of Neurology, Wilhelmina Gasthuis, Amsterdam, The Netherlands
}

SUMMARY The effect of dexamethasone, given thrice weekly, on neuromuscular blocking by D-tubocurarine was studied in mice. Dexamethasone antagonised the effect of D-tubocurarine. This antagonism developed gradually during the first two weeks of treatment. The possible relationship between this finding and the beneficial effect of glucocorticosteroids in patients with myasthenia gravis is discussed.

It was recently shown that the blockage of neuromuscular transmission caused by D-tubocurarine or by low dosage hemicholinium-3 in mice in vivo was antagonised by prednisolone (Arts and Oosterhuis, 1975). Wolters and Leeuwin (1976) suggested that this direct effect of glucocorticosteroids on the neuromuscular transmission might be explained by an increased availability and/or production of the transmitter. From this evidence, it is tempting to suggest that the favourable results reported in patients with myasthenia gravis treated with glucocorticosteroids could be partly or wholly explained by this direct effect of the steroid on neuromuscular transmission. However, the results of the acute experiment (Arts and Oosterhuis, 1975) do not explain why many patients with myasthenia gravis show no, or even an adverse, reaction in the first phase of treatment with steroids, and usually improve gradually after 10 to 14 days of treatment.

The experiment reported here was started to investigate (1) whether the effect of dexamethasone on the neuromuscular block caused by Dtubocurarine could also be demonstrated when dexamethasone was given chronically three times a week, in a dosage comparable with that usually given to humans, and (2) what was the evolution of this effect in the course of the treatment with dexamethasone.

\footnotetext{
${ }^{1}$ Address for reprint requests: Dr Arts, Department of Neurology, Academic Hospital at the University of Amsterdam, Wilhelmina Gasthuis, Eerste Helmersstraat 104, Amsterdam, The Netherlands.

${ }^{2}$ Present address: Department of Neurology, Academic Hospital, Oostersingel 59, Groningen, The Netherlands.

Accepted 31 Desember 1976
}

\section{Methods}

The experiments were done in essentially the same way as described by Arts and Oosterhuis (1975). The sensitivity to D-tubocurarine of inbred female Swiss mice was tested repeatedly before, during, and after a prolonged series of dexamethasone injections given three times a week. The time elapsing between the moment of falling off the rotating rod (Turner, 1965) rotating at $12 \mathrm{rpm}$, and the moment at which the mouse was again able to walk steadily on the rotating rod for at least 20 minutes, was taken as a measure of the effect of D-tubocurarine. D-tubocurarine was injected intraperitoneally in a dosage of $40 \mu \mathrm{g} / 100 \mathrm{~g}$ of body weight. The experiments were done at about $1300 \mathrm{~h}$, at a constant temperature and degree of humidity. Dexamethasone was chosen as the most suitable corticosteroid, first because it was found that dexamethasone has a stronger antagonising effect on the neuromuscular block caused by hemicholinium-3 (Wolters and Leeuwin, 1976), and second because it has no mineralocorticoid side effects. After two control experiments to determine the sensitivity of each mouse to Dtubocurarine, 20 mice were injected subcutaneously with dexamethasone disodium phosphate in aqueous solution over a period of 50 days on Monday, Wednesday, and Friday. The dosage used was $3 \mu \mathrm{g}$ in $0.3 \mathrm{ml}$ of $0.9 \% \mathrm{NaCl}$. At an average body weight of $20 \mathrm{~g}$ (variation initially 16-19 g, at the end of the experiment 18-24 g) this amounts to $15 \mu \mathrm{g} / 100 \mathrm{~g}$ of body weight. This way of treating the mice is analogous to the 'high singledose alternate day' treatment with prednisone of patients with myasthenia gravis, as described by Warmolts and Engel (1972). 
Table Mean and median value of duration of neuromuscular block (minutes) caused by D-tubocurarine before, during, and after chronic alternate day treatment with dexamethasone in mice

\begin{tabular}{|c|c|c|c|c|c|c|c|c|c|c|c|c|c|c|}
\hline $\begin{array}{l}\text { Experiment number } \\
\text { Number of mice tested } \\
\text { Mean value } \\
\text { Standard deviation } \\
\text { Median value }\end{array}$ & $\begin{array}{l}1 \\
19 \\
14.9 \\
9.7 \\
19.0\end{array}$ & $\begin{array}{l}\text { II } \\
19 \\
14.6 \\
8.4 \\
15.0\end{array}$ & $\begin{array}{l}\text { III } \\
14 \\
9.5 \\
7.4 \\
7.8\end{array}$ & $\begin{array}{r}\text { IV } \\
14 \\
16.0 \\
6.3 \\
14.5\end{array}$ & $\begin{array}{l}V \\
19 \\
4.3 \\
5.3 \\
1.5\end{array}$ & $\begin{array}{l}\text { VI } \\
14 \\
2.4 \\
3.6 \\
0.8\end{array}$ & $\begin{array}{c}\text { VII } \\
19 \\
3.7 \\
4.4 \\
1.5\end{array}$ & $\begin{array}{l}\text { VIII } \\
19 \\
7.3 \\
7.8 \\
6.0\end{array}$ & $\begin{array}{l}\text { IX } \\
19 \\
3.0 \\
4.1 \\
1.0\end{array}$ & $\begin{array}{l}X \\
19 \\
5.0 \\
5.9 \\
4.0\end{array}$ & $\begin{array}{l}X I \\
19 \\
5.6 \\
6.6 \\
3.5\end{array}$ & $\begin{array}{l}\text { XII } \\
19 \\
6.5 \\
5.8 \\
7.5\end{array}$ & $\begin{array}{l}\text { XIII } \\
19 \\
17.9 \\
13.9 \\
16.5\end{array}$ & $\begin{array}{r}\text { XIV } \\
14 \\
17.9 \\
7.9 \\
19.5\end{array}$ \\
\hline
\end{tabular}

The experiments were done in the following order: day 1-11: control experiments (I and II); day 14: first injection of dexamethasone; day 1725: first series of experiments (III and IV).

All mice were tested once on a day on which they had received dexamethasone and once on a day without dexamethasone (on and off days). Experiments on on and off days were done with intervals of two or three days and in random order: day 29-37: second series of experiments (V-VIII); day 49-53: third series of experiments (IX and X); day 63-67: fourth series of experiments (XI and XII); day 70-77: gradually diminishing the dosage of dexamethasone to zero; day 85-94: control experiments (XIII and XIV).

The sensitivity to D-tubocurarine on the on days was tested in experiments III, V, VII, IX, and $\mathrm{XI}$, the sensitivity on the off days in experiments IV, VI, VIII, X, and XII.

Six mice were not treated with dexamethasone. Their sensitivity to D-tubocurarine was tested with the same intervals as in the 20 treated animals. Statistical evaluation of the results was done with Friedman's test and with Wilcoxon's signed rank test.

\section{Results}

One mouse died in experiment IV. The results of the remaining 19 mice are summarised in the Table and the Figure. The results obtained in the control experiments before and after the treatment with dexamethasone (I, II and XIII, XIV) did not differ significantly from each other when compared with Wilcoxon's signed rank test. From the Figure it appears that the reduction of the sensitivity to D-tubocurarine caused by dexamethasone becomes stable after about two weeks of treatment. This reduction of the sensitivity to D-tubocurarine was significant: when experiments I, IV, V, VII, VIII, IX, X, XI, XII, and XIII were compared with Friedman's test, $\chi^{2}$ was 56 and therefore P smaller than $0.1 \%$. Experiment VI only involved 14 observations and was, therefore, not included in the statistical evaluation. It appears from the Figure that the results of experiment VI fit in very well with the other experiments. Experiment XIV could not be in-

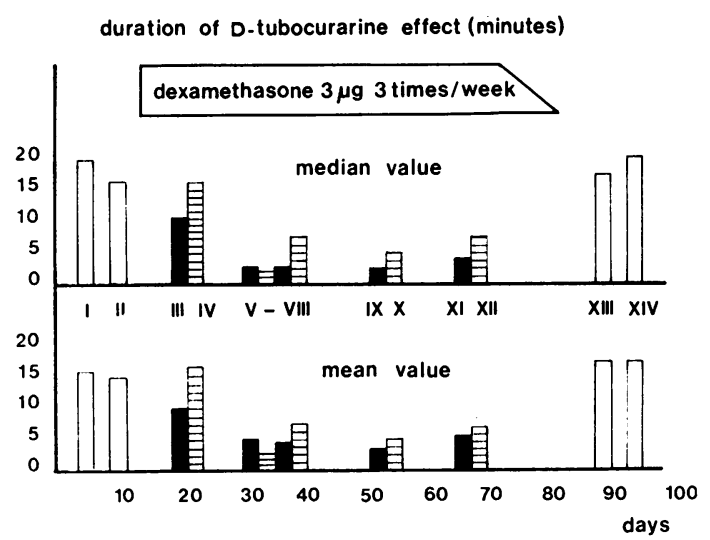

Figure Median and mean values of duration of neuromuscular block before, during, and after dexamethasone treatment in 20 mice.

cluded because five mice died in experiment XIII.

Comparison of the results on the on days with those on the off days of each pair of experiments with Wilcoxon's signed rank test showed that experiments V and VI, IX and X, and XI and XII did not differ significantly from each other, while VII was smaller than VIII at a level of confidence P smaller than $5 \%$. Statistical comparison of the results of such pairs of experiments was deemed justified because the interval between on day and off day experiments was two or three days, while the on day experiment was done first in half of the mice and the off day experiment first in the other half.

Experiments III and IV, performed during the first 10 days of treatment with dexamethasone, should be discussed separately. In each experiment, only 14 out of the 19 mice could be tested. Comparing III and IV showed that III was smaller than IV at a level of confidence P smaller than $5 \%$. As could be expected, the results of experiment IV did not differ significantly from the control experiments. Six mice were not subjected to treatment with dexamethasone. For three of them, repeated tests with D-tubocurarine proved fatal: they died during the second to fifth test. The other three showed a more or less constant sensitivity to D-tubocurarine but their number was too small for statistical evaluation. 


\section{Discussion}

The results of this experiment show that dexamethasone in a dosage comparable with that usually given to patients with myasthenia gravis causes a gradual decrease of the sensitivity to D-tubocurarine in mice, reaching a constant level after about two weeks of alternate day treatment with dexamethasone, when the decrease becomes highly significant with Friedman's test. There is no significant difference between the results on the on and off days. This would mean that the protecting effect of corticosteroids lasts for at least 48 hours, as in the alternate day steroid treatment of myasthenia gravis. The way in which steroids exert their influence is not known. Humoral antibody activity against the acetylcholine receptors found by Bender et al. (1975) and others is commonly thought to be suppressed by steroids, but this is not yet proven. Abramsky et al. (1975) reported that the suppression by prednisone of a cellular immune reaction to receptor protein ran parallel to the improvement of the clinical condition in two patients. However, evidence is accumulating that glucocorticosteroids may also act directly at the neuromuscular junction. An increase in the excitability of the lower motor neurone by steroids was reported by Riker $e t$ al. (1975). In extensive in vitro studies on the phrenic nerve-diaphragm preparation of the rat, Wolters and Leeuwin (1976) showed that corticosteroids, especially dexamethasone, reduced the sensitivity of the preparation to low-dosage hemicholinium-3. Veldsema-Currie et al. (1976) explained this effect by an enhancement of choline uptake and/or acetylcholine synthesis at the presynaptic level.

The in vivo experiments reported here point in the same direction, and also show that the development of the effect of dexamethasone runs parallel to the development of a clinical response to the steroid in patients with myasthenia. This evidence, combined with the findings of the immunological studies, suggests that in patients with myasthenia gravis corticosteroids have a double effect. The indirect effect would consist of sup- pression of the immune reaction against acetylcholine receptors, while the direct effect on neuromuscular transmission could be caused by an increased availability of acetylcholine which in this way would be better able to compete with the receptor-blocking antibodies now thought to be the source of muscular weakness in myasthenia gravis.

We wish to thank Dr P. N. Aarsen, who gave valuable advice about the experimental procedure, and Dr J. Oosting who helped with the statistical procedures.

\section{References}

Abramsky, O., Aharonov, A., Teitelbaum, D., and Fuchs, S. (1975). Myasthenia gravis and acetylcholine receptor. Effects of steroids in clinical course and cellular immune response to acetylcholine receptor. Archives of Neurology (Chicago), 32, 684-687.

Arts, W. F., and Oosterhuis, H. J. (1975). Effect of prednisolone on neuromuscular blocking in mice in vivo. Neurology (Minneapolis), 25, 1088-1090.

Bender, A. N., Ringel, S. P., Engel, W. K., Daniels, M., and Vogel, Z. (1975). Myasthenia gravis: a serum factor blocking acetylcholine receptors of the human neuromuscular junction. Lancet, 1, 607-609.

Riker, W. F., Baker, T., and Okamoto, M. (1975). Glucocorticoids and mammalian motor nerve excitability. Archives of Neurology (Chicago), 32, 688-694.

Turner, R. A. (1965). Screening Methods in Pharmacology, p. 89. Academic Press: New York.

Veldsema-Currie, R. D., Wolters, E., and Leeuwin, R. S. (1976). The effect of corticosteroids and hemicholinium-3 on choline-uptake and incorporation into acetylcholine in rat diaphragm. European Journal of Pharmacology, 35, 399-402.

Warmolts, J. R., and Engel, W. K. (1972). Benefit from alternate-day prednisone in myasthenia gravis. New England Journal of Medicine, 286, 17-20.

Wolters, E., and Leeuwin, R. S. (1976). Effect of corticosteroids on the phrenic nerve-diaphragm preparation treated with hemicholinium. A possible model of myasthenia gravis. Neurology (Minneapolis), 26, 574-578. 